\title{
Fibrinogen in relation to personal history of prevalent hypertension, diabetes, stroke, intermittent claudication, coronary heart disease, and family history: the Scottish Heart Health Study
}

\author{
Amanda J Lee, Gordon D O Lowe, Mark Woodward, Hugh Tunstall-Pedoe
}

\begin{abstract}
Objective-To determine the relations of plasma fibrinogen to family history of premature heart disease, personal history of hypertension, diabetes, stroke, coronary heart disease, and to presence of intermittent claudication.
\end{abstract}

Design-Random population survey across 22 local government districts in Scotland.

Participants-10 359 men and women aged 40 to 59 years. Plasma fibrinogen was measured in 8824 .

Main outcome measure-Plasma fibrinogen concentration.

Results-Persons with a family history of heart disease or a personal history of high blood pressure, diabetes, stroke, or presence of intermittent claudication all had higher plasma fibrinogen concentrations than those without. When compared with participants without cardiovascular or related disease (men: $\mathbf{2 \cdot 2 7}$ $(\mathrm{SE}=\mathbf{0 . 0 1}) \mathrm{g} \boldsymbol{\Lambda}, \quad \mathrm{n}=3367$; women $2 \cdot 34$ $(0.01) \mathrm{g} / \mathrm{l}, \mathrm{n}=3096)$, predefined cases of either myocardial infarction (men: $2 \cdot 51$ $(0.02) \mathrm{g} / \mathrm{l}, \mathrm{n}=248$; women: $2.63(0.04) \mathrm{g} / \mathrm{l}$, $\mathrm{n}=72$ ) or angina (men: $2.45(0.02) \mathrm{g} / \mathrm{l}$, $\mathrm{n}=394$; women: $2 \cdot 50(0 \cdot 02) \mathrm{g} / 1, \mathrm{n}=398)$ had significantly higher plasma fibrinogen concentrations $(p<0.001)$. After adjustment for 10 other coronary risk factors, there was a noticeable linear trend in the odds ratios for myocardial infarction across all quartiles (quarters) of plasma fibrinogen concentrations in both sexes. Similarly, the risk of angina increased linearly with increasing fibrinogen concentrations, although the test for a linear trend was NS among women.

Conclusions-This large population study confirms that plasma fibrinogen is not only a risk factor for coronary heart disease and stroke, but it is also raised with family history of premature heart disease and with personal history of hypertension, diabetes, and presence of intermittent claudication.

(Br Heart $\mathcal{F} 1993 ; 69: 338-342)$

Recently, reports from the follow up of five epidemiological studies have related plasma fibrinogen to the incidence of coronary heart disease. ${ }^{1-5}$ Only two of these, however, the Caerphilly and Speedwell collaborative studies $^{67}$ and the Northwick Park Heart Study 8 have reported the correlation of baseline plasma fibrinogen concentration with prevalent coronary disease. Furthermore, no random population study has related plasma fibrinogen concentrations to family history of premature heart disease, personal history of hypertension, diabetes, or stroke, although cross sectional studies have consistently related plasma fibrinogen to peripheral vascular disease. ${ }^{910}$

In the Scottish Heart Health Study, ${ }^{112}$ plasma fibrinogen was measured in 8824 middle aged men and women. A previous report has examined the relations of plasma fibrinogen to coronary risk factors in this population. ${ }^{13}$ With so many participants the strength and consistency of any relations $N$ reported in previous smaller studies can be $N$ tested. Also, as we have data on both sexes, $\widetilde{O}$ any sex differences in the association between 0 fibrinogen and prevalent disease can be explored. Our paper reports the relations of ? plasma fibrinogen with family history of heart 7 disease and with personal history of hyper- $\frac{}{\mathbb{D}}$ tension, diabetes, stroke, peripheral vascular disease (as indicated by intermittent claudica- 0 tion), and with prevalent coronary heart disease.

Patients and methods

The Scottish Heart Health Study was a random population survey of 10359 men and women aged 40 to 59 years across 22 local government districts of Scotland. Each subject was sent an extensive questionnaire to 
complete, covering demographic details and lifestyle. This was checked at the screening clinic, where height and weight were measured, a blood sample taken, and an electrocardiogram carried out.

Family history of premature heart disease was ascertained by asking if a subject's parents or brothers and sisters had heart disease before the age of 60 years. A subject's medical history was elicited by the question "Have you ever been told by a doctor that you have, or have had, any of the following?" The options were high blood pressure, stroke, diabetes, angina, and heart attack (coronary thrombosis, myocardial infarction). The Rose symptom questionnaire was used to assess angina, possible previous myocardial infarction, and intermittent claudication. ${ }^{14}$ Additional evidence of prevalent coronary heart disease was from the electrocardiogram, this was coded with the Minnesota codes, ${ }^{15}$ with codes $1 \cdot 1$ to $1 \cdot 2$ signifying a $Q / Q S$ pattern of myocardial infarction and codes $1 \cdot 3$, $4 \cdot 1$ to $4 \cdot 4,5 \cdot 1$ to $5 \cdot 3$ and $7 \cdot 1$ showing ischaemic changes based on the Whitehall categories. ${ }^{16}$

In the case control analysis, the two most specific criteria were used to define the cases. Hence, people with myocardial infarction were defined as those with a medical history or a $\mathrm{Q} / \mathrm{QS}$ pattern on the electrocardiogram. A medical history or chest pain on the Rose questionnaire was evidence of angina. Subjects with evidence of both myocardial infarction and angina were classified as a case of myocardial infarction. The remaining participants were used as the control group with the following exclusions: any evidence of prevalent cardiovascular disease, treatment for high blood pressure, and taking vasodilators or cardiovascular drugs. Definitions and methods of measurement of the other risk factors have been reported previously. ${ }^{11}$ Plasma fibrinogen was measured in 8824 samples of stored citrated plasma by the thrombin time method of Clauss, ${ }^{17}$ with a Coag-U-Mate X2 coagulometer (Organon Teknika) with the manufacturer's reagents and standards.

\section{STATISTICAL METHODS}

Student's $t$ test (two-tailed) was used to examine the significance of differences in mean plasma fibrinogen concentrations. Adjusted means (SEs) were calculated with PROC GLM in SAS. ${ }^{18}$ In the case control analysis, the Generalised Linear Interactive Modelling system (GLIM) was used to calculate age adjusted odds ratios for each quartile (quarter) of the fibrinogen distribution with the first quartile as base. ${ }^{19}$ The significance of these odds ratios and tests for both a linear trend and a non-linear residual effect were also calculated. In the multivariate case control analyses, the odds ratios were further adjusted for systolic blood pressure, total and high density lipoprotein cholesterol, triglyceride, uric acid, body mass index, smoking and drinking state, and family history of premature heart disease. These variables have
Table 1 Mean (SE) plasma fibrinogen ( $g / l$ ) by premature parental and sibling history of premature heart disease (standardised for age and smoking)

\begin{tabular}{lll}
\hline & Men & Women \\
\hline $\begin{array}{l}\text { Parental history: } \\
\text { Yes }\end{array}$ & $\begin{array}{l}2 \cdot 34(0.01) \\
\mathrm{n}=896\end{array}$ & $\begin{array}{l}2 \cdot 41(0.01) \\
\mathrm{n}=1135\end{array}$ \\
No & $\begin{array}{l}2 \cdot 30(<0.01)^{\star \star \star} \\
2 \cdot 36(<0.01)^{\star \star \star}\end{array}$ & $\mathrm{n}=2931$ \\
Sibling history: & $\mathrm{n}=3344$ & \\
Yes & $2 \cdot 34(0.01)$ & $2 \cdot 46(0 \cdot 01)$ \\
No & $\mathrm{n}=497$ & $\mathrm{n}=558$ \\
& $2 \cdot 32(<0.01)^{\star}$ & $2 \cdot 38(<0.01)^{\star \star \star}$ \\
& $\mathrm{n}=3307$ & $\mathrm{n}=3051$ \\
\hline
\end{tabular}

${ }^{\star} \mathrm{p}<0.05 ;{ }^{\star \star \star} \mathrm{p}<0.001$ for history $v$ no history ( $t$ tests).

previously been shown to affect fibrinogen concentrations in this population. ${ }^{13}$ Finally, the sex effect was investigated further as both a main effect and also for its interaction with plasma fibrinogen.

\section{Results}

Table 1 shows that subjects with either a parental or a sibling history of premature heart disease had significantly higher fibrinogen concentrations than those without (after standardisation for age and smoking).

Subjects with a self reported medical history of high blood pressure, diabetes, or stroke, and those with intermittent claudication had higher mean plasma fibrinogen concentrations than subjects with no disease, after standardisation for age, body mass index, and smoking (table 2). Some of these associations were statistically significant in men only.

\section{MYOCARDIAL INFARCTION}

Compared with those participants without cardiovascular or related disease, men and women with any of the three indicators of myocardial infarction (medical history, chest pain on the Rose questionnaire, and electrocardiogram) all had significantly higher plasma fibrinogen concentrations than those without (table 3). When the interrelations of the three indicators were examined, those

Table 2 Mean (SE) plasma fibrinogen ( $g / l$ ) by medical history (standardised for age, body mass index, and smoking)

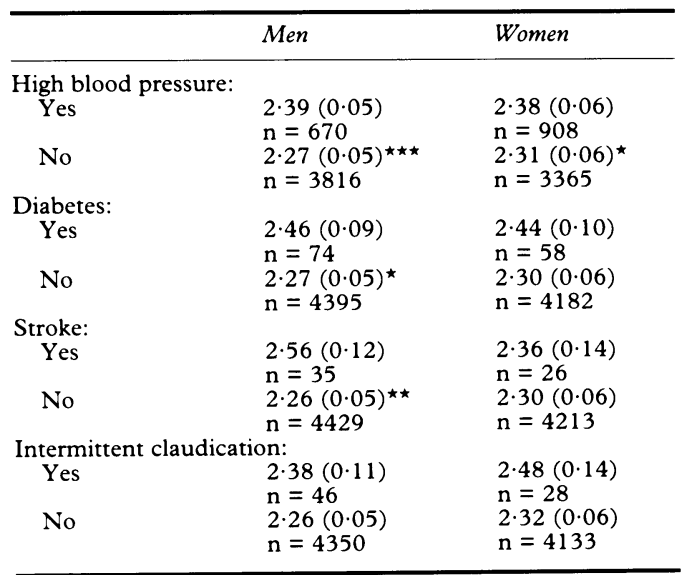

${ }^{\star} \mathrm{p}<0.05 ;{ }^{\star \star} \mathrm{p}<0.01 ;{ }^{\star \star \star} \mathrm{p}<0.001$ for history $v$ no history ( $t$ tests). 
Table 3 Mean (SE) plasma fibrinogen ( $g / l)$ by indicators of myocardial infarction

\begin{tabular}{lll}
\hline $\begin{array}{l}\text { Indicators of } \\
\text { myocardial infarction }\end{array}$ & Men & Women \\
\hline Medical history & $2 \cdot 55(0 \cdot 05)^{\star \star \star}$ & $2 \cdot 80(0 \cdot 11)^{\star \star \star}$ \\
& $\mathrm{n}=209$ & $\mathrm{n}=58$ \\
Rose chest pain & $2 \cdot 40(0 \cdot 04)^{\star \star \star}$ & $2 \cdot 56(0 \cdot 06) \star \star \star$ \\
questionnaire & $\mathrm{n}=306$ & $\mathrm{n}=181$ \\
Electrocardiogram (Q/QS) & $2 \cdot 61(0.09) \star \star \star$ & $2 \cdot 62(0 \cdot 12)^{\star}$ \\
No cardiovascular & $\mathrm{n}=90$ & $\mathrm{n}=24$ \\
or related disease & $2 \cdot 27(0.01)$ & $2 \cdot 34(0 \cdot 01)$ \\
& $\mathrm{n}=3367$ & $\mathrm{n}=3096$ \\
\hline
\end{tabular}

${ }^{\star} \mathrm{p}<0.05 ;{ }^{\star \star \star} \mathrm{p}<0.001$ for indicator $v$ no disease group (t tests)

subjects with two or more indicators of disease had higher fibrinogen values than those with only one. These effects were not simply due to age as this was comparable across all seven subgroups for both sexes (data not shown).

The age standardised mean (SE) fibrinogen values for men were $2.51(0.02) \mathrm{g} / \mathrm{l},(\mathrm{n}=$ 248) among cases of myocardial infarction and $2.27(0.01) \mathrm{g} / \mathrm{l}, \quad(\mathrm{n}=3367)$ among

Figure 1 Odds ratios for myocardial infarction by plasma fibrinogen $(\mathrm{g} / \mathrm{l})$ (arranged in quartiles).
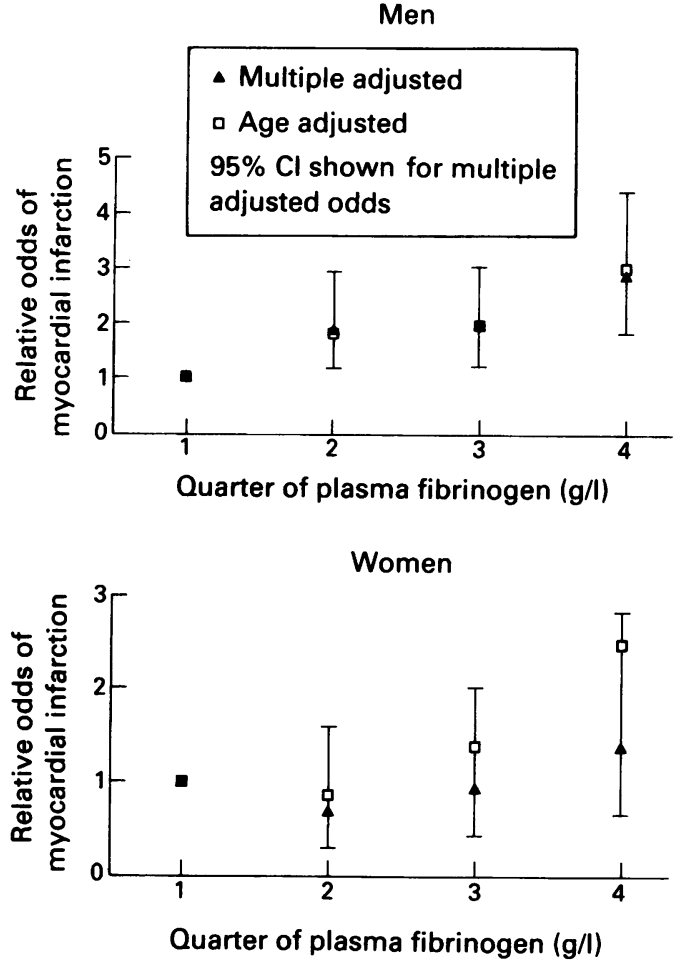

Table 4 Numerical data for figure 1

\begin{tabular}{|c|c|c|}
\hline \multirow[b]{2}{*}{ Adjustments } & \multicolumn{2}{|l|}{ Odds ratio $(95 \% \mathrm{CI})$} \\
\hline & Men & Women \\
\hline $\begin{array}{l}\text { Second quartile: } \\
\text { Age } \\
\text { Multi }\end{array}$ & $\begin{array}{l}1.79(1.15-2.79)^{\star} \\
1.84(1.17-2.91)^{\star}\end{array}$ & $\begin{array}{l}0.85(0.37-1.93) \\
0.66(0.28-1.58)\end{array}$ \\
\hline $\begin{array}{l}\text { Third quartile: } \\
\text { Age } \\
\text { Multi }\end{array}$ & $\begin{array}{l}1.94(1.25-3.00)^{\star \star} \\
1.92(1.22-3.02)^{\star \star}\end{array}$ & $\begin{array}{l}1.38(0.66-2.90) \\
0.91(0.42-2.00)\end{array}$ \\
\hline $\begin{array}{l}\text { Fourth quartile: } \\
\text { Age } \\
\text { Multi }\end{array}$ & $\begin{array}{l}2.99(1.97-2 \cdot 53)^{\star \star \star} \\
2.82(1.81-4.38)^{\star \star \star}\end{array}$ & $\begin{array}{l}2.45(1.24-4.83)^{\star \star} \\
1.35(0.65-2.81)\end{array}$ \\
\hline $\begin{array}{l}\text { Test for linear trend } \\
\text { Age } \\
\text { Multi }\end{array}$ & : & $\star \star$ \\
\hline
\end{tabular}

Table 5 Mean (SE) plasma fibrinogen ( $g / l)$ by indicators of angina and ischaemia

\begin{tabular}{lll}
\hline Indicators of angina & Men & Women \\
\hline Medical history & $2 \cdot 53(0 \cdot 05)^{\star \star \star}$ & $2 \cdot 57(0 \cdot 05)^{\star \star \star}$ \\
& $\mathrm{n}=236$ & $\mathrm{n}=157$ \\
Rose chest pain & $2 \cdot 48(0 \cdot 05)^{\star \star \star}$ & $2 \cdot 50(\theta \cdot 05)^{\star \star \star}$ \\
questionnaire & $\mathrm{n}=248$ & $\mathrm{n}=299$ \\
Electrocardiogram & $2 \cdot 44(0 \cdot 05)^{\star \star \star}$ & $2 \cdot 42(0 \cdot 03)^{\star \star}$ \\
(Whitehall-ischaemia) & $\mathrm{n}=363$ & $\mathrm{n}=391$ \\
No cardiovascular or & $2 \cdot 27(0 \cdot 01)$ & $2 \cdot 34(0 \cdot 01)$ \\
related disease & $\mathrm{n}=3367$ & $\mathrm{n}=3096$ \\
\hline
\end{tabular}

${ }^{\star \star} \mathrm{p}<0.01 ;{ }^{\star \star \star} \mathrm{p}<0.001$.

subjects without cardiovascular or related disease $(p<0.001)$. For women, the figures were $2.63(0.04) \mathrm{g} / \mathrm{l},(\mathrm{n}=72)$ and $2.34(0.01)$ $\mathrm{g} / \mathrm{l},(\mathrm{n}=3096)(\mathrm{p}<0.001)$.

Figure 1 and table 4 show the age adjusted and multiple adjusted odds ratios for myocardial infarction across all quartiles of plasma fibrinogen concentrations. The odds ratios were consistently higher for men than for women. The male odds ratios were statistically significant in all quartiles of plasma fibrinogen and showed a significant linear trend $(p<$ 0.001 ), with no significant non-linear residual effect. Among women, the age adjusted odds ratio was significant $(p<0.01)$ for only the top quartile of plasma fibrinogen concentrations. There was, however, a significant linear trend $(\mathrm{p}<0.01)$. After multiple adjustment, none of the female odds ratios reached statistical significance. An investigation into the effect of sex on plasma fibrinogen concentrations found that there was a consistent significant main effect (women had higher concentrations), but no significant interaction.

ANGINA

Subjects with any evidence of angina had significantly higher plasma fibrinogen concentrations than those subjects without cardiovascular or related disease (table 5). When the interrelations between the three indicators were examined, subjects with two or more indicators present had the highest plasma fibrinogen concentrations. Once again, the mean age was comparable across the seven subgroups (data not shown).

The age standardised mean (SE) plasma fibrinogen values were significantly higher among prevalent angina cases (men: 2.45 $(0.02) \mathrm{g} / \mathrm{l},(\mathrm{n}=394)$; women: $2.50(0.02) \mathrm{g} / \mathrm{l}$, $(n=398)$ ) than among those subjects without cardiovascular or related disease (men: $2.27(0.01) \mathrm{g} / \mathrm{l}, \quad(\mathrm{n}=3367)$; women: 2.34 $(0.01) \mathrm{g} / \mathrm{l},(\mathrm{n}=3096)(\mathrm{p}<0.001))$.

When the distribution of fibrinogen was split into quartiles, a consistent linear effect in the male odds ratios was noted, with the risk of angina increasing as plasma fibrinogen concentration increased (fig 2 and table 6). Tests of a linear trend in the odds ratio were significant for each sex $(p<0.001)$. Among women, the age adjusted odds ratios were significant for the third and fourth quartiles of fibrinogen concentrations, but these effects became non-significant after multiple adjustment. There was no sex effect on the age adjusted odds ratios for angina. For the 
Figure 2 Odds ratios for angina by plasma fibrinogen $(g / l)$ (arranged in quartiles).
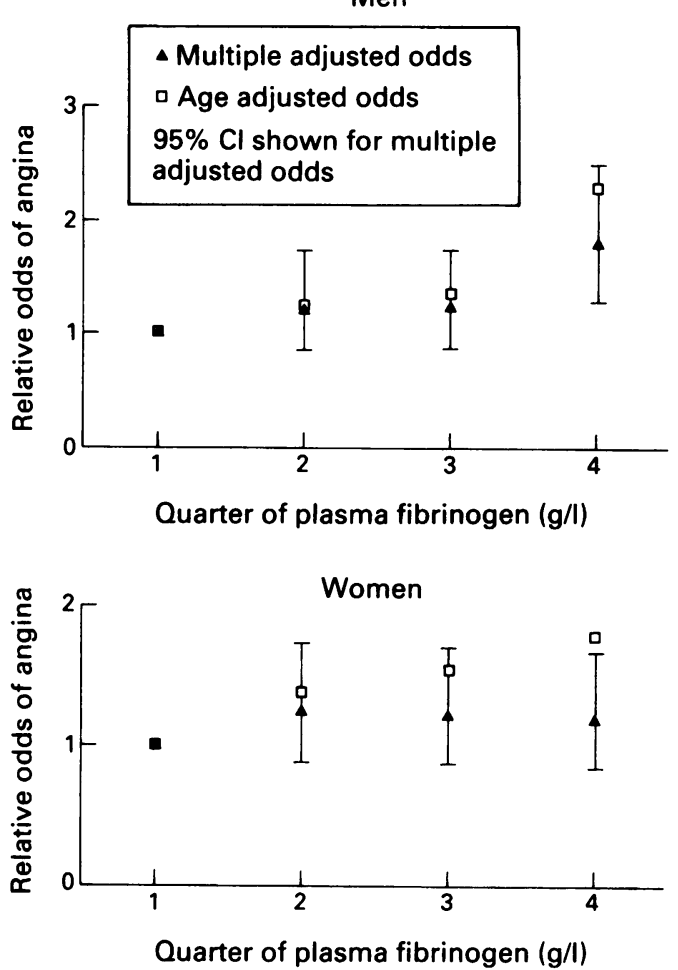

multiple adjusted odds ratios, however, there was a significant effect of $\operatorname{sex}(p<0.001)$ and a significant interaction of sex with plasma fibrinogen concentration $(p<0.05)$.

\section{Discussion}

In this cross sectional analysis of a large random population sample across Scotland, there were significant associations of plasma fibrinogen concentration with family history of premature heart disease and also with prevalent peripheral vascular disease, coronary heart disease, and hypertension. Subjects who reported a medical history of diabetes or stroke each had higher plasma fibrinogen concentrations than those with no history. In the case control analyses, the risk of having either myocardial infarction or angina increased as plasma fibrinogen concentration increased: the effects were more striking among men than among women.

There is much evidence that people with a family (parental or sibling) history of premature heart disease have an increased risk of developing it themselves. ${ }^{20}{ }^{21}$ Also, a parental

Table 6 Numerical data for figure 2

\begin{tabular}{|c|c|c|}
\hline \multirow[b]{2}{*}{ Adjustments } & \multicolumn{2}{|l|}{ Odds ratio $(95 \% \mathrm{CI})$} \\
\hline & Men & Women \\
\hline \multicolumn{3}{|c|}{ Second quartile: } \\
\hline Age & $1.25(0.90-1.75)$ & $1.37(0.99-1.89)$ \\
\hline Multi & $1.22(0.86-1.72)$ & $1.24(0.89-1.73)$ \\
\hline \multicolumn{3}{|c|}{ Third quartile: } \\
\hline $\begin{array}{l}\text { Age } \\
\text { Multi }\end{array}$ & $1.36(0.98-1.89)$ & $1.53(1 \cdot 11-2 \cdot 10)^{\star \star}$ \\
\hline \multicolumn{3}{|c|}{ Fourth quartile: } \\
\hline $\begin{array}{l}\text { Age } \\
\text { Multi }\end{array}$ & $\begin{array}{l}2 \cdot 29(1 \cdot 68-3 \cdot 12)^{\star \star \star} \\
1.80(1 \cdot 29-2 \cdot 49)^{\star \star}\end{array}$ & $\begin{array}{l}1.77(1.29-2.42)^{\star \star \star} \\
1.18(0.84-1.66)\end{array}$ \\
\hline \multicolumn{3}{|c|}{ Test for linear trend: } \\
\hline Age & 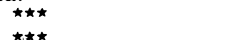 & $\star \star$ \\
\hline Multi & $\star \star \star \star$ & \\
\hline
\end{tabular}

history seems to contribute to risk independently of other factors. ${ }^{21-24}$ Our finding that family history of premature heart disease is associated with increased plasma fibrinogen concentrations, in combination with evidence of heritability of fibrinogen concentrations, ${ }^{25} 26$ suggest that the genetic component of fibrinogen concentrations may be one contributor to the heritability of premature heart disease.

Cardiovascular disease is an important cause of both morbidity and mortality of diabetic patients. We have confirmed the results of previous studies that plasma fibrinogen concentrations are raised in diabetic people. ${ }^{27}$ After adjustment for age, body mass index, and smoking, we found that our 74 male and 58 female diabetic subjects had higher plasma fibrinogen concentrations than non-diabetic subjects. This raised plasma fibrinogen concentration may play a part in the cardiovascular complications of diabetes. ${ }^{29}$ Our finding that prevalent stroke is associated with raised plasma fibrinogen concentrations is consistent with a recent case control study of transient ischaemic attacks and minor strokes ${ }^{30}$ and with two prospective studies. ${ }^{14}$ A more detailed analysis of the current data related tertiles of plasma fibrinogen concentration to the prevalence of intermittent claudication. ${ }^{31}$ It found that the odds ratios were statistically significant among men, even after adjustment for other coronary risk factors. There was, however, no apparent effect among women. Data from the Framingham study showed a raised plasma fibrinogen concentration in subjects who subsequently progressed to having peripheral vascular disease. ${ }^{9}$ Another study noted a raised plasma fibrinogen concentration in patients with intermittent claudication and also the higher the concentration the worse the disease. ${ }^{10}$

We have shown that prevalent coronary heart disease (myocardial infarction or angina) is associated with increased plasma fibrinogen concentrations, confirming previous studies. $^{6-8}$ After inclusion of several variables that were associated with plasma fibrinogen concentrations in our study, ${ }^{13}$ the strength of association between plasma fibrinogen and prevalent coronary heart disease was reduced, especially for angina in women (fig 2). The appropriateness of multivariate analysis may, however, be questioned, because variables such as smoking may promote cardiovascular disease by increasing plasma fibrinogen concentrations. Subjects in our study who had been diagnosed as having coronary heart disease reported both reduced cigarette consumption and an increase in giving up smoking. ${ }^{32}$ However, with cotinine as an objective measure of smoking, this group inhaled the most tobacco. It is unlikely that drugs used for treatment of coronary heart disease, hypertension, or diabetes significantly affected plasma fibrinogen concentrations. ${ }^{33}$

Results from the current analyses show that plasma fibrinogen, unlike, for example, serum cholesterol, is raised in all aspects of 
disease from a family history of premature heart disease to a personal history of hypertension, stroke, diabetes, peripheral vascular, and coronary heart disease. We noted, however, that some of these associations were stronger among men. This may, in part, have been due to the higher prevalence of disease among men..$^{34}$ Alternatively, there may be real biological differences between the sexes that might explain the results. A history of high blood pressure, stroke, diabetes, angina, and myocardial infarction based on self report has not been validated within this study. Any loss of specificity and sensitivity would, however, tend to dilute the difference in plasma fibrinogen concentration between the history and no history groups, rather than abolish them.

It is interesting that we confirmed a raised fibrinogen concentration in subjects with angina. This suggests that fibrinogen may have a role in the narrowing of vessels before the start of thrombosis. It may also be involved in the pathogenesis of hypertension, although its predictive value cannot be entirely accounted for by its correlations with blood pressure or other risk factors. We have previously reported weak correlations between plasma fibrinogen and systolic blood pressure on entry to this population (rank correlations of 0.01 in men and 0.13 in women)..$^{13}$

Results from one of the largest epidemiological studies of plasma fibrinogen reported to date confirm the importance of plasma fibrinogen as an important cardiovascular risk factor. Follow up of the participants in the Scottish Heart Health Study, currently in progress, will enable us to estimate the relative contribution of plasma fibrinogen concentrations to incidence of cardiovascular disease in a population with very high levels of coronary heart disease.

The Scottish Heart Health Study was funded by the Chief Scientist's Office of the Scottish Home and Health Department; however, the views expressed in this article are those of the authors and not the Department. We thank laboratory staff in the Department of Medicine, Glasgow Roya Infirmary for technical assistance.

1 Wilhelmsen L, Svärdsudd K, Korsan-Bengsten $\mathrm{K}$ Larsson B, Welin L, Tibblin G. Fibrinogen as a risk factor for stroke and myocardial infarction. $N$ Engl $\mathcal{F}$ Med 1984;311:501-5.

2 Stone MC, Thorp JM. Plasma fibrinogen-a major coronary risk factor. $\mathcal{f} R$ Coll Gen Pract 1985;35:565-9.

3 Meade TW, Mellows S, Brozovic M, et al. Haemostatic function and ischaemic heart disease: principal results of the Northwick Park Heart Study. Lancet 1986;ii:533-7.

4 Kannel WB, Wolf PA, Castelli WP, D'Agostino RB Fibrinogen and risk of cardiovascular disease. The Framingham Study. $\mathcal{F} A M A$ 1987;258:1183-6.

5 Yarnell JWG, Baker IA, Sweetnam PM, et al. Fibrinogen, viscosity and white blood cell count are major risk factors for ischaemic heart disease. The Caerphilly and Speedwell Collaborative Heart Disease Studies. Circulation 1991;83:836-44.

6 Baker IA, Eastham R, Elwood PC, Etherington M, O'Brien JR, Sweetnam PM. Haemostatic factors associated with ischaemic heart disease in men aged 45 to 64 years. The Speedwell study. Br Heart $\mathcal{f}$ 1982;47:490-4.

7 Yarnell JWG, Sweetnam PM, Elwood PC, et al. Haemostatic factors and ischaemic heart disease. The
Caerphilly study, Br Heart f 1985;53:483-7.

Meade TW. Epidemiology of atheroma, thrombosis and ischaemic heart disease. In: Bloom AL, Thomas DP, eds. Haemostasis and thrombosis. 2nd ed. Edinburgh: Churchill Livingstone. 1987;697-720.

9 Kannel WB, D'Agostino RB. Update of fibrinogen as a major cardiovascular risk factor: the Framingham study [abstract]. F Am Coll Cardiol 1990;15:156A.

10 Dormandy JA, Hoare E, Colley J, Arrowsmith JE, Dormandy TL. Clinical, haemodynamic and biochemical findings in 126 patients with intermittent claudication. Br Med F 1973;4:576-81.

11 Smith WCS, Tunstall-Pedoe H, Crombie IK, Tavendale R. Concomitants of excess coronary deaths: major risk factor and lifestyle findings from 10359 men and women in the Scottish Heart Health Study. Scot Med $\mathfrak{F}$ 1989;34:550-5.

12 Tunstall-Pedoe $\mathrm{H}$, Smith WCS, Crombie IK, Tavendale R. Coronary risk factor and lifestyle variation across Scotland: results from the Scottish Heart Health Study. Scot Med F 1989;34:556-60.

13 Lee AJ, Smith WCS, Lowe GDO, Tunstall-Pedoe H. Plasma fibrinogen and coronary risk factors: the Scottish Heart Health Study. $f$ Clin Epidemiol 1990;43:913-9.

14 Rose G, McCartney P, Reid DD. Self administration of a questionnaire on chest pain and intermittent claudication. British fournal of Preventative and Social Medicine 1977;31:42-8.

15 Prineas RJ, Crow RS, Blackburn $H$. The Minnesota code manual of electrocardiographic findings. London: John Wright, 1982

16 Rose G, Baxter PJ, Reid DD, McCartney P. Prevalence and prognosis of electrocardiographic findings in middle-aged men. Br Heart $\mathcal{f}$ 1978;40:636-43.

17 Clauss A. Gerrinnungephysiologische schnellmethode sur bestimmung des fibrinogens. Acta Haematol (Basel) 1957;17:237-46

18 SAS Institute. SAS User's Guide: statistics. 5th ed. Cary, NC: SAS Institute, 1985.

19 Payne $C D$, ed. The generalised linear interactive modelling ystem release 3.77 manual. London: Royal Statistical Society, 1986.

20 Myers RH, Kiely OK, Cupples LA, Kannel WB. Parental history is an independent risk factor for coronary artery disease: the Framingham study. Am Heart $f$ 1990;120:963-9.

21 Colditz GA, Rimm EB, Giovannucci E, Stampfer MI Rosner B, Willett WC. A prospective study of parental history of myocardial infarction and coronary artery disease in men. Am $\mathcal{F}$ Cardiol 1991;67:933-8.

22 Jorde LB, Williams RR. Relation between family history of coronary artery disease and coronary risk variables. Am $\mathcal{F}$ Cardiol 1988;62:708-13.

23 Phillips AN, Shaper AG, Pocock SJ, Walker M. Parental death from heart disease and the risk of heart attack. Eur Heart $\mathcal{f}$ 1988;9:243-51.

24 Friedlander Y, Kark JD, Stein Y. Family history of myocardial infarction as an independent risk factor for coronary heart disease. Br Heart $\mathcal{f} 1985 ; 53: 382-7$.

25 Hamsten A, Iselius L, De Faire U, Blomback M. Genetic and cultural inheritance of plasma fibrinogen concentraand cultural inheritance of plast

26 Humphries SE, Cook M, Dubowitz M, Stirling Y, Meade TW. Role of genetic variation at the fibrinogen locus in determination of plasma fibrinogen concentrations. Lancet $1987 ; \mathbf{i}: 1452-5$.

27 Fuller JH, Keen H, Jarrett RJ, et al. Haemostatic variables associated with diabetes and its complications. $\mathrm{Br} M e d \mathcal{F}$ 1979;2:964-6.

28 Kannel WB, D'Agostino RB, Wilson PWF, Belanger AJ, Gagnon DR. Diabetes, fibrinogen and the risk of cardiovascular disease: the Framingham experience. $\mathrm{Am}$ Heart $\mathcal{F} 1990 ; 120: 672-6$.

29 McRury SM, Lowe GDO. Blood rheology in diabetes mellitus. Diabetic Medicine 1990;7:285-91.

30 Qizilbash N, Jones L, Warlow C, Mann J. Fibrinogen and lipid concentrations as risk factors for transient ischaemic attacks and minor ischaemic strokes. $\mathrm{Br}$ Med ischaemic attacks

31 Smith WCS, Woodward $M$, Tunstall-Pedoe $H$ Intermittent claudication in Scotland. In: Epidemiology of peripheral vascular disease. Fawkes FGR, ed. London: Springer-Verlag, 1991;117-23.

32 Woodward $M$, Tunstall-Pedoe $H$. Biochemical evidence of persistent heavy smoking after a coronary diagnosis despite self-reported reduction: analysis from the Scottish Heart Health Study. Eur Heart $\mathcal{f}$ 1992;13:160-5.

33 Lowe GDO. Rheological therapy. In: Lowe GDO, ed. Clinical Blood Rheology. Volume 2. Boca Raton: CRC Press, 1988;1-22.

34 Smith WCS, Kenicer MB, Tunstall-Pedoe H, Clark EC, Crombie IK. Prevalence of coronary heart disease in Scotland: Scottish Heart Health Study. Br Heart $\mathcal{f}$ 1990;64:295-8. 